\title{
THE CONTROVERSIAL ROLE OF MDM-2, MCM-3 AND BCL-X IN AMELOBLASTOMA AND AMELOBLASTIC CARCINOMA: AN UPDATE
}

\author{
Nagla M Salama*, Eman Hany** and Doaa AM Esmaeil ${ }^{* * *}$
}

\begin{abstract}
Background: Although great strides were made toward understanding the pathogenesis of ameloblastoma, the malignant transformation potential remains understudied. This study introduces an updated view on the involvement of MDM-2, MCM-3, and Bcl-X in ameloblastoma variants and ameloblastic carcinoma.
\end{abstract}

Aim: This study aims to investigate the etiopathogenesis controversial role of MDM-2, MCM3 , and $\mathrm{Bcl}-\mathrm{X}$ in ameloblastoma variants and ameloblastic carcinoma.

Methodology: Forty cases were included in the current study, thirty cases of ameloblastoma and ten cases of ameloblastic carcinoma that were immunohistochemically stained for MDM-2, MCM-3, and Bcl-X antibodies.

Results: Statistically significant positive expression of MDM-2, MCM-3, and Bcl-X in ameloblastic carcinoma than ameloblastoma variants. Positive expression was highly detected in conventional, ameloblastoma than unicystic ameloblastoma.

Conclusion: Immunoreactivity for MDM-2, MCM-3, and Bcl-X in ameloblastoma variants and ameloblastic carcinoma suggests that these antibodies might be associated with tissue structuring and cytodifferentiation of ameloblastomas and aggressiveness of ameloblastic carcinoma. High levels of MCM-3 and MDM-2 proteins expression are more sensitive in predicting growth rate of tumors.

KEYWORDS: Ameloblastoma; ameloblastic carcinoma; Oncogenesis; MDM-2; MCM-3; Bcl-X.

\footnotetext{
* Associate Professor of Oral Pathology Department, Faculty of Dentistry, Mansoura University; Associate Professor of Oral Pathology Department, Faculty of Dentistry, Horus University, Egypt.

** Lecturer of Oral Biology Department, Faculty of Dentistry, Mansoura University, Egypt.

***Lecturer of Oral Pathology Department, Faculty of Dentistry, Mansoura University, Egypt.
} 


\section{INTRODUCTION}

Ameloblastoma (AM) is the most frequently encountered benign, yet locally aggressive, epithelial odontogenic tumor of the oral cavity. Based on WHO $2017^{[1]}$, ameloblastomas are simply divided into i. conventional, ii. unicystic type, iii. peripheral type, and iv. metastasizing ameloblastoma. The etiopathogenesis of AM explored at the molecular ${ }^{[2]}$, epigenetic ${ }^{[3]}$, immunohistochemical levels ${ }^{[4]}$ with evidence pointing at FGFR2-RAS-BRAF mutations ${ }^{[2]}$, dysregulation of mitogen-activated protein kinase, sonic hedgehog, and WNT/ $\beta$ catenin signaling pathways, somatic copy number alterations, copy-neutral loss of heterozygosity, and apoptosis-related gene BcL2L11 ${ }^{[2-7]}$.

Ameloblastic carcinoma (AC) denotes ameloblastic lesions with a lack of differentiation, hypercellularity, conspicuous mitotic activity, necrosis, vascular and neural invasion, and a less differentiated histomorphology. If $\mathrm{AC}$ sent a metastasis, the designation "malignant (metastasizing) ameloblastoma" would be used. Yoon et al. $2009^{[8]}$ reviewed 98 previously reported cases and reported 6 new ones. They concluded that AC prefers the posterior mandible and males as twice as they hit maxilla in females. The mean age was 49.2 years. AC usually manifests itself as an asymptomatic swelling that turns symptomatic. Ulceration, paresthesia, and trismus are also evident ${ }^{[8]}$.

MDM-2 is a specific marker to identify proliferative activity and tumor aggressiveness by immunohistochemistry, a $90-95 \mathrm{kDa}$ protein coded by the $\mathrm{mdm} 2$ gene is mapped on chromosome 12q13-14 ${ }^{[9,10]}$. MDM-2 protein overexpression generally results from gene amplification and concomitant appearance of double minutes (Murine Double Minute) ${ }^{[11]}$. Overexpression of MDM-2 is usually associated with poor prognosis and has been reported in various human cancers including breast carcinomas, malignant melanomas, esophageal carcinomas, soft tissue sarcomas, osteosarcomas, lung, and bronchogenic carcinomas, leukemias, lymphomas, and head and neck cancers ${ }^{[12]}$.

The minichromosome maintenance-3 (MCM-3) protein is a nuclear protein associated with DNA replication that predicts the biological and clinical behaviors that is used as a diagnostic or prognostic marker in various tumors ${ }^{[13,14]}$. It is one member of Minichromosome maintenance (MCM) proteins family, which consists of eight members, including MCM2-MCM7 complex ${ }^{[15]}$. Owing to its expression in early G1 phase of cell cycle, so MCM-3 is better than other proliferation markers for evaluating tumor behavior ${ }^{[13]}$.

Apoptosis, also known as programmed cell death, plays a diverse role in embryogenesis, the development, and maintenance of normal homeostasis as well as in oncogenesis and is associated with the pathogenesis of various tumors. An imbalance among the antiapoptotic proteins such as Bcl-2 family members could induce dysregulation of apoptosis, which would contribute to oncogenesis and tumor development ${ }^{[15]}$. Bcl-X, a $20 \mathrm{kDa}$ protein a newly discovered member of the Bcl-2 antiapoptotic protein family, and very little data exist on the expression of $\mathrm{Bcl}-\mathrm{X}$ in various types of ameloblastoma, and ameloblastic carcinoma.

This study, therefore, aimed to investigate whether MDM-2, MCM-3, and Bcl-X proteins are expressed by various types of ameloblastoma, and ameloblastic carcinoma and if so whether or not there is a statistically significant difference in expression between ameloblastoma and ameloblastic carcinoma, indicating that these proteins might play a role in tumor progression and growth profile determination of these tumors in an attempt to elucidate its influence on their biological behavior, aggressive nature inherent in them.

\section{MATERIAL AND METHODS}

This retrospective study was carried out on forty archival paraffin blocks that include 30 cases 
previously diagnosed as ameloblastomas, and 10 cases of ameloblastic carcinomas, obtained from the Oral Pathology Department, Faculty of Dentistry, and Pathology Department, Faculty of Medicine, Mansoura University. AB was classified according to WHO classification of Head and Neck tumors published in $2017^{[1]}$.

\section{Histological Study}

Two sections of $4 \mu \mathrm{m}$ thickness from each paraffin block were cut, deparaffinized, rehydrated, and stained with (a) routine hematoxylin and eosin stain (H\&E) for re-evaluation, confirmation of histopathological examination \& diagnosis and to classify the cases to different histopathological types according to the WHO criteria (b) for the immunohistochemical evaluation of MDM-2, MCM-3, and Bcl-X expression, positively charged glass slides (Optiplus) Biogenex, San Ramon, California, USA, were used for immunostaining procedures.

\section{Immunohistochemical study:}

Sections de-paraffinized and subjected to heatinduced antigen retrieval method using citrate buffer (10mM, pH 6.0) in a pressure cooker for 2 min. To block endogenous peroxidase activity, the samples were treated with $3 \%$ hydrogen peroxide solution for $15 \mathrm{~min}$. Subsequently, the sections were incubated for $4 \mathrm{~h}$ with primary monoclonal antibodies MDM2 (clone SMP14) (diluted 1:50 in TRIS$\mathrm{Hcl}$ (pH 7.6), MCM3 and Bcl-X (Ready-to-use vial, BioGenex) 1:50 dilution in TRIS-Hcl (pH 7.6), followed by 45 minutes in secondary antibody (rabbit anti-mouse immunoglobulins) (DAKO, Denmark). They were then immersed in streptavidin-biotin peroxidase conjugate (DAKO) and incubated for 10 min with 3, 3-diaminobenzidine chromogen (DAKO). The sections were then counter-stained with Mayer's hematoxylin before mounting. All the steps were carried out at room temperature and after each step, the sections were washed with TRIS-Hcl buffer (pH 7.6).
To guard against false-negative and false-positive results, negative and positive control sections were included in all runs. Negative control sections were performed by omitting the primary antibodies and substituting them with phosphate-buffered saline (PBS) non-immune serum for MDM-2, MCM3 , and Bcl-X. A positive reaction was indicated by the presence of brown-colored end products at the area of target antigens.

\section{Staining assessment}

Quantitation of immunoreactivity was performed using an Olympus light microscope interfaced via Sony camera to an image analysis system (Qwin Pro, Leica, Wetzlar, Germany). The percentages of MDM2, MCM3, and Bcl-X immuno-positive cells were obtained from 20 random fields per case/section using a $10 \times$ objective lens. This performed in image analysis unite in Microbiology Department, Faculty of Medicin, Mansoura University.

\section{Evaluation of immunostaining}

The percentage of positive cells was scored according to the method of Kumamoto and Ooya 1999 ${ }^{[16]}$ as follows: $0=$ negative (less than $5 \%$ positive cells or no staining); weak staining $=+1(5-24 \%$ positive); moderate staining $=+2(25-50 \%$ positive); strong staining $=+3$ (more than $50 \%$ positive).

\section{Statistical analysis}

Data were tabulated, coded then analyzed using the computer program SPSS (Statistical package for social science) version 17.0 to obtain Descriptive data which was calculated in the form of:

1. Median \& range for quantitative nonparametric data.

2. Frequency (Number-percent) for qualitative data

\section{Analytical statistics}

The significance of difference was examined in 
the statistical comparison between the groups using one of the following tests:

Mann-Whitney test: Used to compare between two unrelated groups of numerical (non-parametric) data. A P value $<0.05$ was considered statistically significant in all analyses. Spearman correlation coefficient test was used to correlating different parameters.

\section{RESULTS}

\section{Histopathological findings:}

The present study was carried out on 40 cases classified as 30 cases of AMs that include 20 cases of conventional type (15 follicular AM, 5 plexiform $\mathrm{AM})$, the remaining 10 cases were unicystic type (4 luminal AM and 6 mural AM), and 10 cases of ameloblastic carcinomas, confirmation of histopathological diagnosis were done by hematoxylin and eosin stain (H.\&E.). Follicular AM cases are presented as multiple islands of odontogenic epithelial cells, with peripheral tall columnar cells with reverse polar nucleus and central stellate reticulum like cells surrounded by connective tissue stroma, while in plexiform AM showed anastomosing strands of epithelium, the outer cells are cuboidal and the inner cells are loosely arranged few stellate reticulum like cells within stroma. Mural unicystic AM is cyst space lined by epithelium with cuboidal basal cells and stallete reticulium like cells with budding of epithelium in connective tissue forming multiple nests and cords of odontogenic epithelium. Luminal unicystic AM are showed as cyst cavity lined by odontogenic epithelium with epithelium thickening toward cyst lumen. The AC cases showed areas exhibit squamous differentiation with obvious cytological atypia as cellular pleomorphism, nuclear hyperchromatism, and abnormal mitosis (Fig.1).

\section{Immunohistochemical staining}

a. MDM-2 immunostaining was seen in the nucle- us and cytoplasm of peripheral cells and central stellate reticulum-like cells of neoplastic islands of all histopathological variants of AM, however all AC cases were shown with strong expression $\mathbf{5 0}>$ of cells positive stained (Chart 1). Conventional (follicular than plexiform) of AM was expressed more than unicystic (mural than luminal) with statistically significant differences between groups with $\mathrm{P}$ value 0.01 (Chart $2 \& 3$ ) (Fig.2) (Table I). Some connective tissue fibroblasts showed positive nuclear immunostaining.

b. Regarding MCM-3 immunostaining in the studied groups revealed strong +ve nuclear expression in all AC cases $100 \%$ of cases $\mathbf{5 0}>$ of cells stained (Chart 4). While, MCM-3 immunostaining in AM cases were 17 (56.7\%) of cases strong immunoexpression, $11(36.7 \%)$ moderate expression, and 2 (6.6\%) mild immunoreactivities as illustrated in (Table II) (Chart 5) and (Fig. 3 ), as a follicular variant with higher immunoreactivity than plexiform and unicystic subtypes (Chart 6). A high statistically significant difference was noted between the studied groups with a P-value $<0.001 *$ (Table II).

c. Bcl-X immunoreactivity was significantly different between AC cases and AM (Chart 8). $55 \%$ of conventional AM were moderate Bcl$\mathrm{X}$ immunostaining while $35 \%$ of cases were strong Bcl-X immunostaining, however $80 \%$ of unicystic cases were moderate expression (Chart10). Follicular cases (40\% strong Bcl-X expression) were more than plexiform $(20 \%$ strong Bcl-X expression) in conventional and mural (33,3\% strong Bcl-X expression)than luminal ( $0 \%$ strong $\mathrm{Bcl}-\mathrm{X}$ expression) in unicystic ameloblastoma with a statistically significant differences between groups with P-value 0.01 * (Table III) (Fig.4)(Chart 9).

There was moderate positive correlation noted between MDM-2, MCM-3 and BcL-X but with no statistically significant difference (Table IV) 

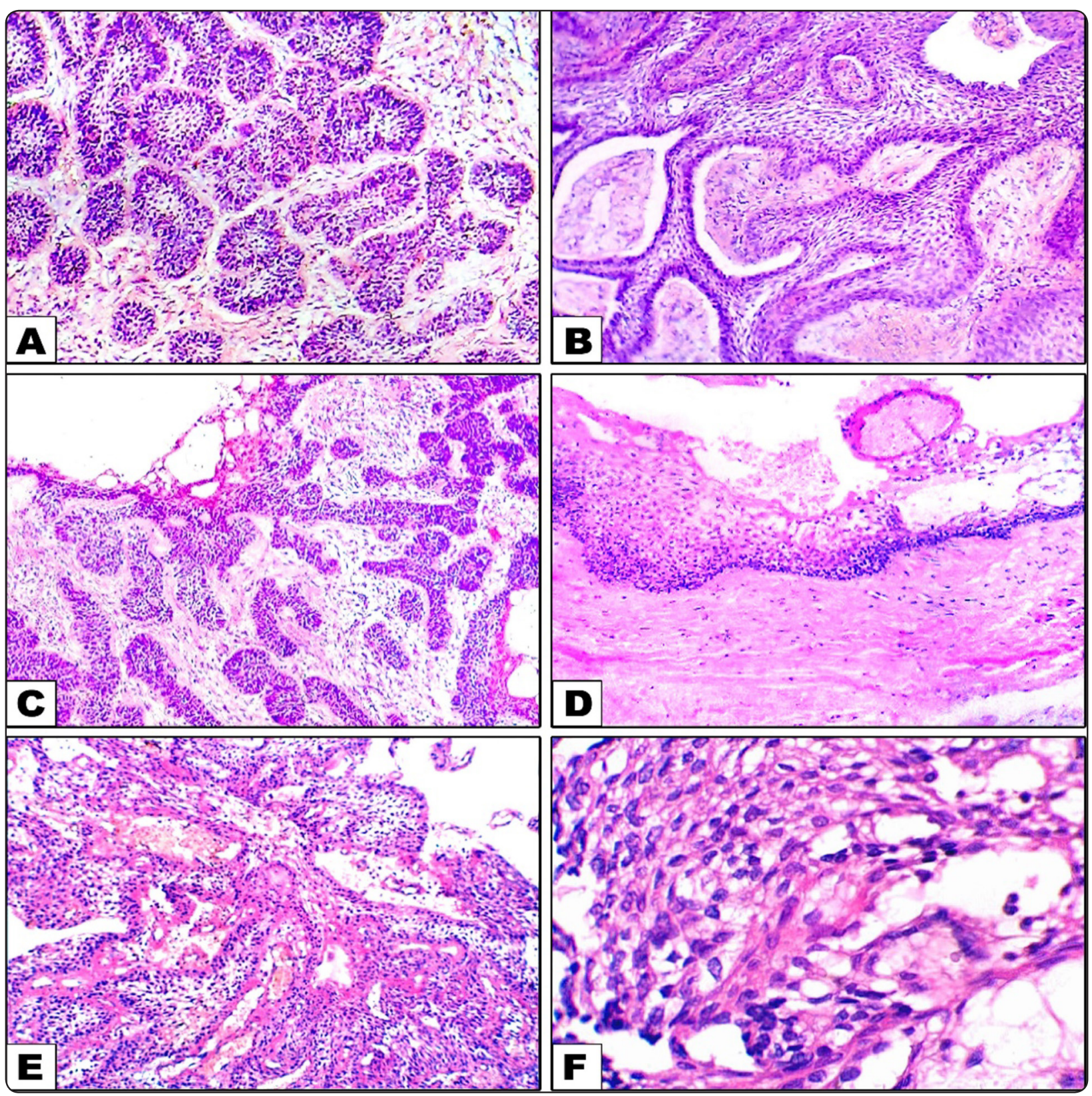

Fig. (1) Hematoxylin and eosin staining of the studied groups: A Follicular conventional ameloblastoma (X 200), B Plexiform conventional ameloblastoma (X 200), C Mural unicystic ameloblastoma (X 200), D Luminal unicystic ameloblastoma (X 200), E Ameloblastic carcinoma (X 200), and F Higher magnification of ameloblastic carcinoma section show cytological atypia as cellular pleomorphism, nuclear hyperchromatism (X 400). 

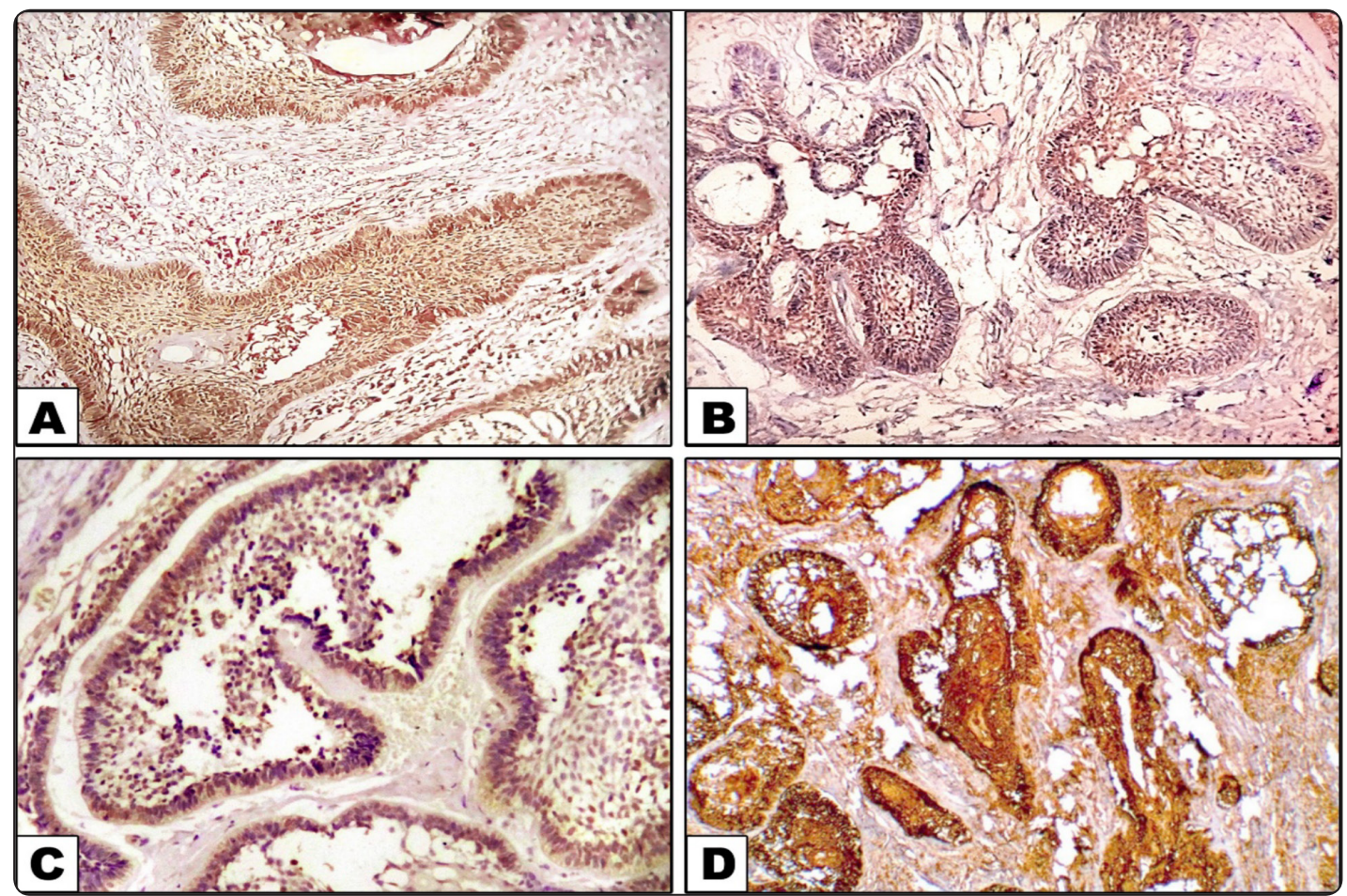

Fig. (2): Immunohistochemical expression of MDM-2 in: A Ameloblastic carcinoma (X200), B Follicular conventional ameloblastoma (X 200), C Plexiform ameloblastoma (X 200), and D Mural unicystic ameloblastoma (X 200); showing cytoplasmic reactivity in most odontogenic epithelial cells.
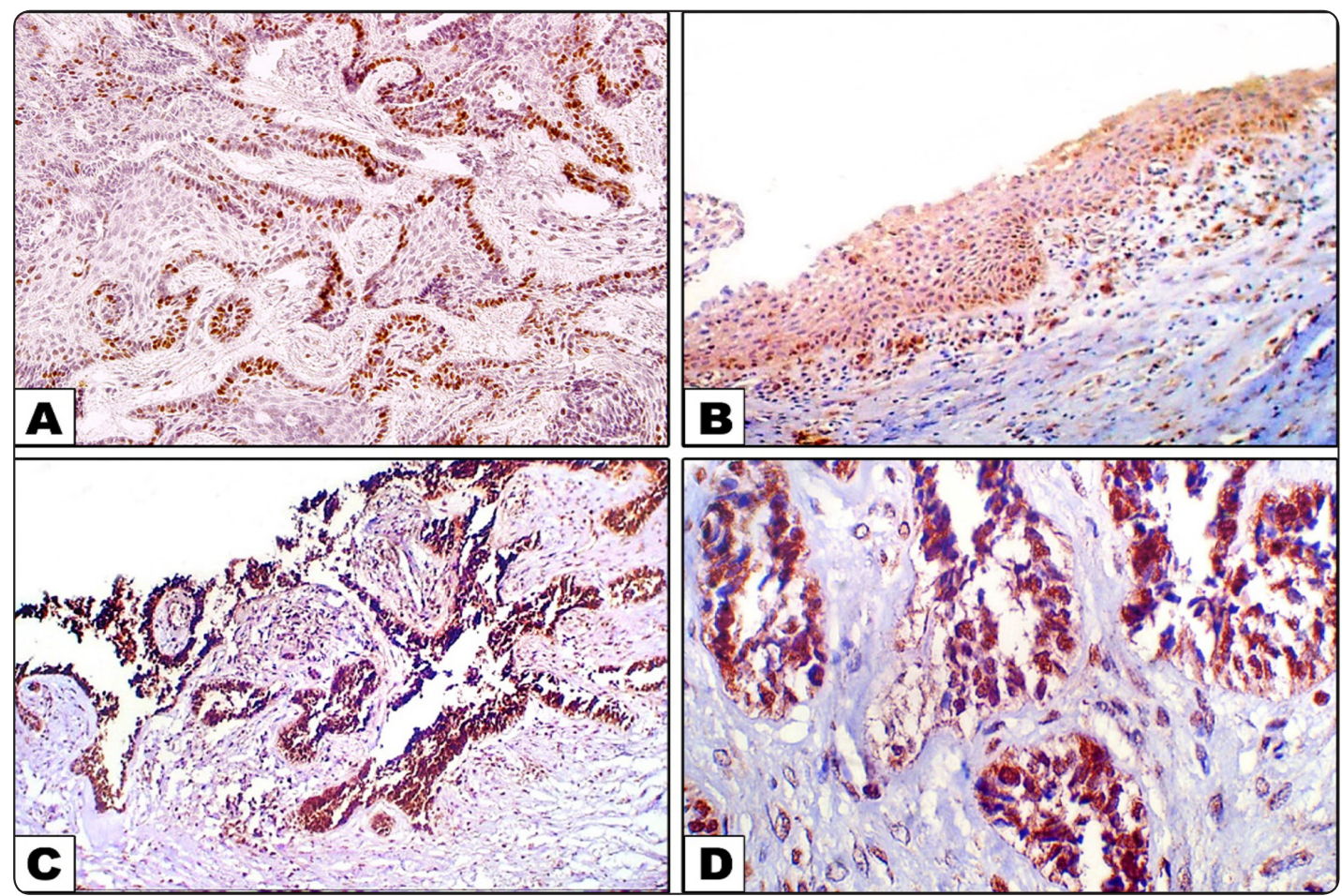

Fig. (3): Immunohistochemical expression of MCM-3 in: A Ameloblastic carcinoma (X 200), B Unicystic luminal ameloblastoma (X 200), C Unicystic mural ameloblastoma (X 100), and D Follicular conventional ameloblastoma (X 400); showing reactivity in most odontogenic epithelial cells. 


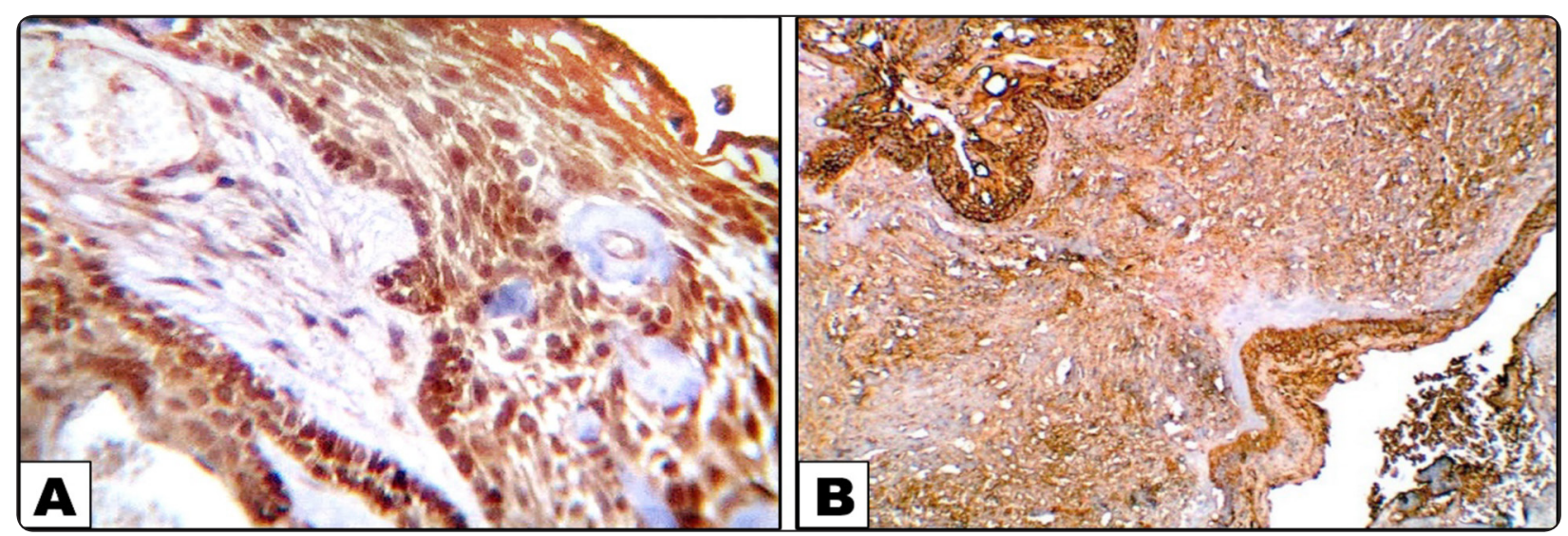

Fig. (4): Immunohistochemical expression of Bcl-X in: A Ameloblastic carcinoma (X400), and B Mural unicystic ameloblastoma (X 200); showing cytoplasmic reactivity in most odontogenic epithelial and stromal cells.

TABLE (I): MDM-2 immunoreactivity of the studied groups:

\begin{tabular}{|c|c|c|c|c|c|c|}
\hline \multirow[b]{2}{*}{ Tumor type } & & \multicolumn{4}{|c|}{ MDM-2 immunoreactivity } & \multirow[b]{2}{*}{$\mathbf{P}$} \\
\hline & & (-)negative & $\begin{array}{c}\text { (+)mild } \\
5-24\end{array}$ & $\begin{array}{c}(++) \text { moderate } \\
25-50\end{array}$ & $\begin{array}{c}(+++) \text { strong } \\
<50\end{array}$ & \\
\hline Ameloblastoma & $(30)$ & $0(0 \%)$ & $10(33.3 \%)$ & $13(43.3 \%)$ & $7 \quad(23.3 \%)$ & $0.01 *$ \\
\hline Solid/multicystic & $(20)$ & $0(0 \%)$ & $3(15.0 \%)$ & $11(55.0 \%)$ & $6(30 \%)$ & \\
\hline Follicular & (15) & $0(0 \%)$ & $1(6.7 \%)$ & $8 \quad(53.3 \%)$ & $6(40 \%)$ & \\
\hline Plexiform & $(5)$ & $0(0 \%)$ & $2(40 \%)$ & $3(60 \%)$ & $0(0 \%)$ & \\
\hline Unicystic & $(10)$ & $0(0 \%)$ & $6(60 \%)$ & $2(20 \%)$ & $2(20 \%)$ & \\
\hline Luminal & (4) & $0(0 \%)$ & $4(100 \%)$ & $0(0 \%)$ & $0(0 \%)$ & \\
\hline Mural & (6) & $0(0 \%)$ & $2(33.3 \%)$ & $2(33.3 \%)$ & $2(33.3 \%)$ & \\
\hline Ameloblastic carcinoma & (10) & $0(0 \%)$ & $0(0 \%)$ & $0 \quad(0 \%)$ & $10(100 \%)$ & \\
\hline
\end{tabular}

Data expressed as frequency (Number-percent)

P: Probability

*: significance $<0.05$ The test used: Monte-Carlo

TABLE (II). MCM-3 immunoreactivity of the studied groups:

\begin{tabular}{|c|c|c|c|c|c|c|}
\hline \multirow[b]{2}{*}{ Tumor type } & & \multicolumn{4}{|c|}{ MCM-3 immunoreactivity } & \multirow[b]{2}{*}{$\mathbf{P}$} \\
\hline & & (-) negative & $\begin{array}{c}(+) \text { mild } \\
5-24\end{array}$ & $\begin{array}{c}(++) \text { moderate } \\
25-50\end{array}$ & $\begin{array}{c}(+++) \text { strong } \\
<50\end{array}$ & \\
\hline Ameloblastoma & $(30)$ & $0(0 \%)$ & $2(6.6 \%)$ & $11(36.7 \%)$ & $17(56.7 \%)$ & \multirow{8}{*}{$<0.001 *$} \\
\hline Solid/multicystic & (20) & $0(0 \%)$ & $1(5 \%)$ & $10(50.0 \%)$ & $9 \quad(45 \%)$ & \\
\hline Follicular & $(15)$ & $0(0 \%)$ & $0(0 \%)$ & $7(46.7 \%)$ & $8 \quad(53.3 \%)$ & \\
\hline Plexiform & (5) & $0(0 \%)$ & $1(20 \%)$ & $3(60.0 \%)$ & $1 \quad(20 \%)$ & \\
\hline Unicystic & $(10)$ & $0(0 \%)$ & $2(20 \%)$ & $6(60.0 \%)$ & $2(20 \%)$ & \\
\hline Luminal & (4) & $0(0 \%)$ & $0(0 \%)$ & $4(100 \%)$ & $0 \quad(0 \%)$ & \\
\hline Mural & $(6)$ & $0(0 \%)$ & $2(33.3 \%)$ & $2(33.3 \%)$ & $2(33.3 \%)$ & \\
\hline Ameloblastic carcinoma & (10) & $0(0 \%)$ & $0(0 \%)$ & $0(0 \%)$ & $10(100 \%)$ & \\
\hline
\end{tabular}


TABLE (III): Bcl-X immunoreactivity of the studied groups:

\begin{tabular}{|c|c|c|c|c|c|c|}
\hline \multirow[b]{2}{*}{ Tumor type } & & \multicolumn{4}{|c|}{ Bcl-X immunoreactivity } & \multirow[b]{2}{*}{$\mathbf{P}$} \\
\hline & & (-) negative & $\begin{array}{c}(+) \text { mild } \\
5-24\end{array}$ & $\begin{array}{c}(++) \text { moderate } \\
25-50\end{array}$ & $\begin{array}{c}(+++) \text { strong } \\
>\mathbf{5 0}\end{array}$ & \\
\hline Ameloblastoma & (30) & $0(0 \%)$ & $9(30 \%)$ & $13(43.3 \%)$ & $8(26.7 \%)$ & \multirow{8}{*}{$0.01 *$} \\
\hline Solid/multicystic & (20) & $0(0 \%)$ & $2(10 \%)$ & $11(55 \%)$ & $7(35 \%)$ & \\
\hline Follicular & (15) & $0(0 \%)$ & $0(0 \%)$ & $9(60 \%)$ & $6(40 \%)$ & \\
\hline Plexiform & (5) & $0(0 \%)$ & $2(40 \%)$ & $2(40 \%)$ & $1(20 \%)$ & \\
\hline Unicystic & (10) & $0(0 \%)$ & $2(20 \%)$ & $8(80 \%)$ & $0(0 \%)$ & \\
\hline Luminal & (4) & $0(0 \%)$ & $4(100 \%)$ & $0(0 \%)$ & $0(0 \%)$ & \\
\hline Mural & (6) & $0(0 \%)$ & $0(60 \%)$ & $4(66.7 \%)$ & $2(33,3 \%)$ & \\
\hline Ameloblastic carcinoma & (10) & $0(0 \%)$ & $0(0 \%)$ & $0(0 \%)$ & $10(100 \%)$ & \\
\hline
\end{tabular}

Data expressed as frequency (Number-percent) $\quad$ P: Probability $\quad *$ : significance $<0.05 \quad$ The test used: Monte-Carlo

TABLE (IV) Correlations between MDM-2, MCM-3 and BcL-X expressions among the studied cases.

\begin{tabular}{cccc}
\hline & \multicolumn{1}{c}{$\begin{array}{c}\text { MDM-2 } \\
\text { expression }\end{array}$} & $\begin{array}{c}\text { MCM-3 } \\
\text { expression }\end{array}$ \\
\hline \multirow{2}{*}{ BcL-X expression } & r & 0.586 & 0.603 \\
\cline { 2 - 4 } & P & 0.076 & 0.0932 \\
\hline \multirow{2}{*}{ MCM-3 expression } & r & 0.655 & \\
\cline { 2 - 4 } & P & 0.097 & \\
\hline
\end{tabular}

r: Spearman's rho correlation coefficient P: Probability

$P$ value $\leq 0.05$ was considered statistically significant

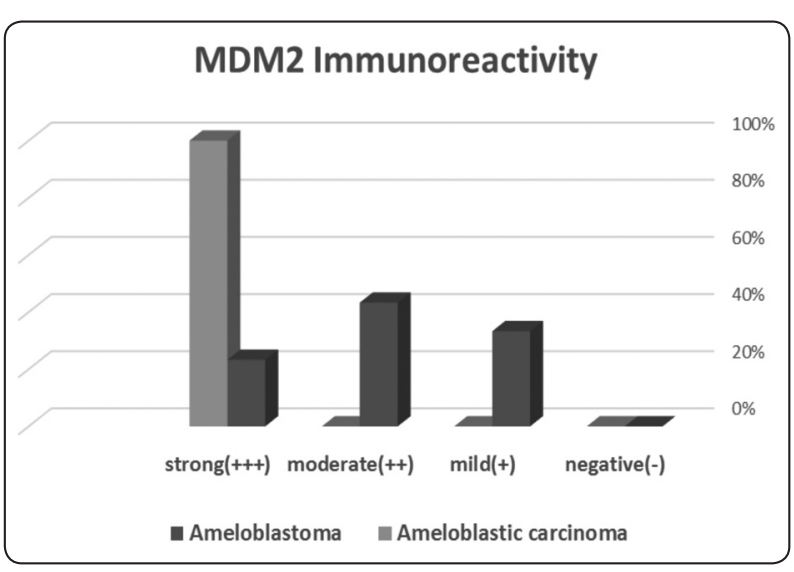

Chart (1): MDM2 Immunoreactivity among study AM \& AC:

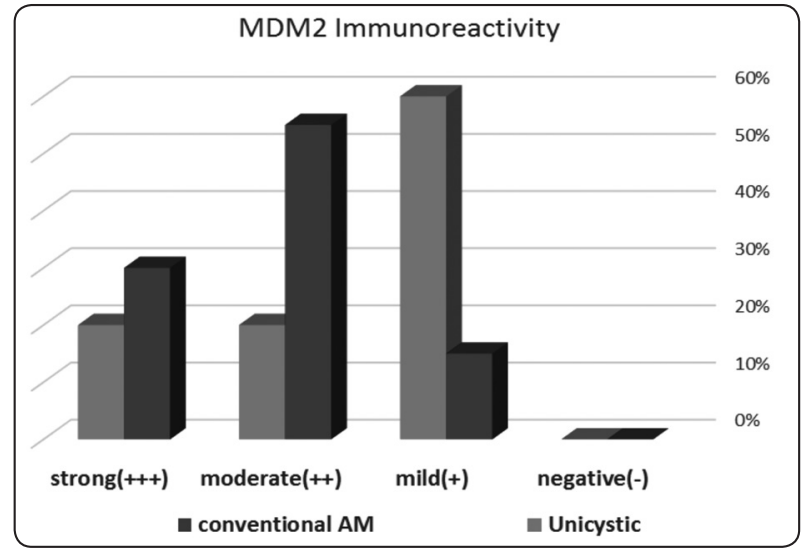

Chart (2): MDM2 Immunoreactivity among conventional AM and unicystic AM:

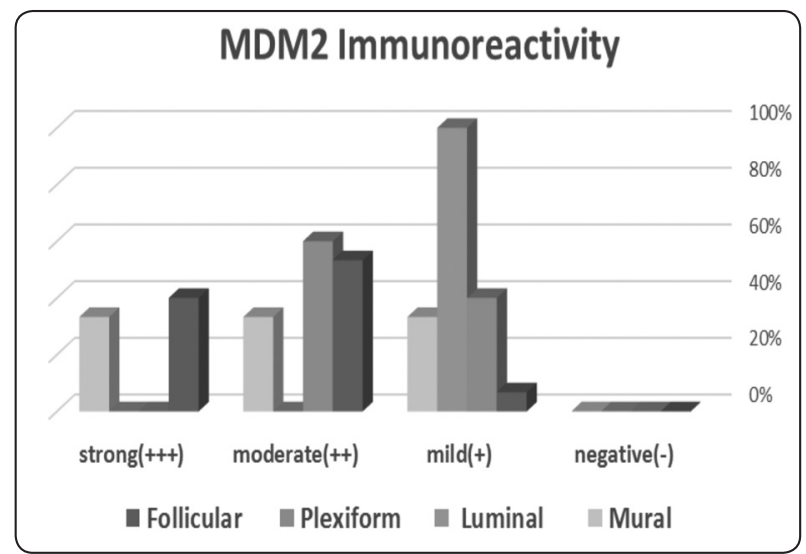

Chart (3): MDM2 Immunoreactivity among studied variants of AM: 


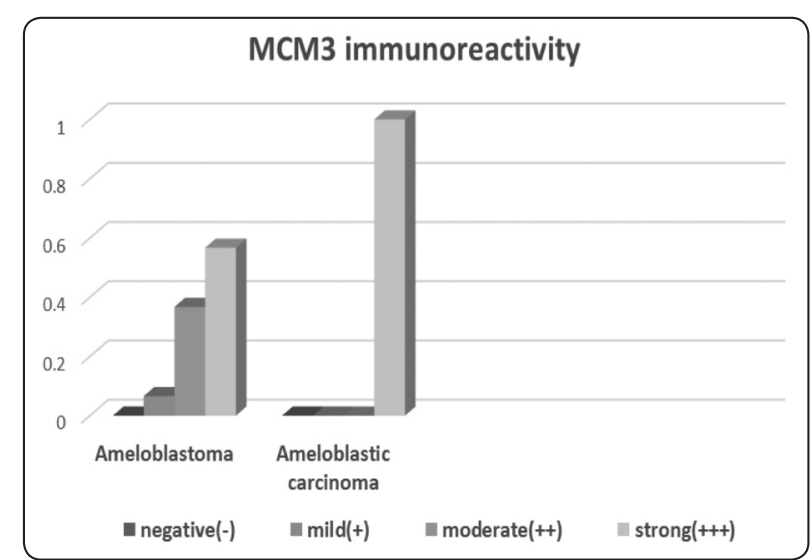

Chart (4): MCM3 immunoreactivity among AM and AC.

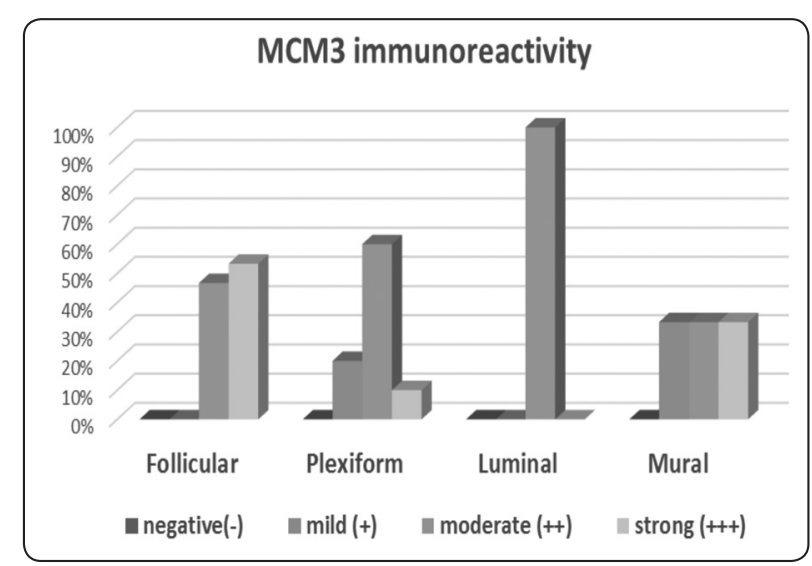

Chart (6): MCM3 immunoreactivity among AM variants:

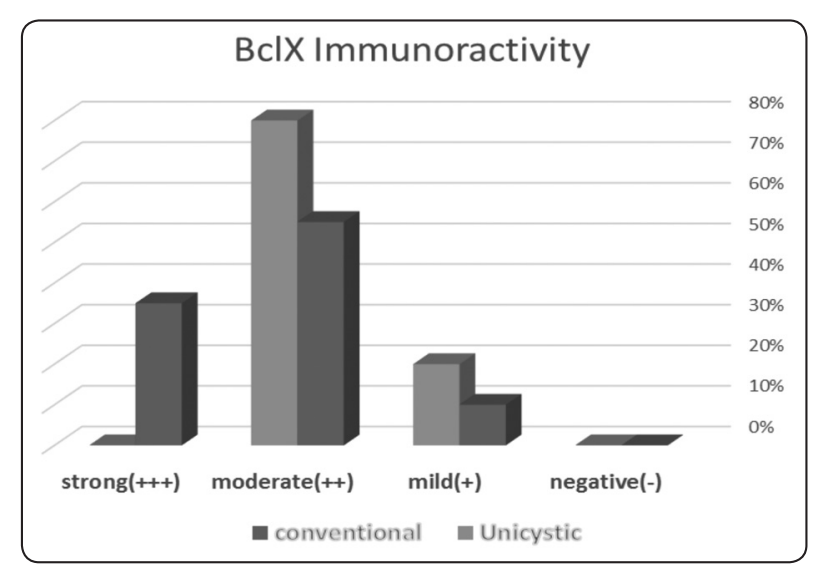

Chart (8): BcLX immunoreactivity among studied conventional AM variant and unicystic AM:

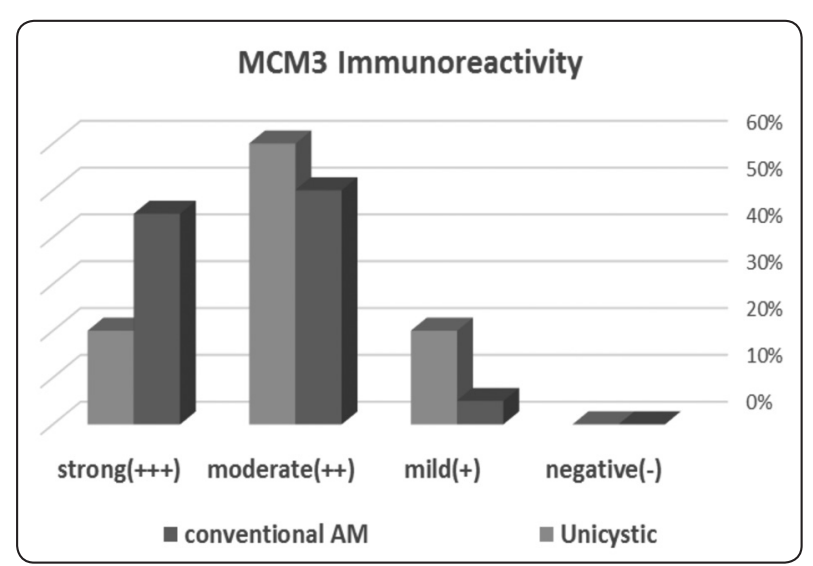

Chart (5): MCM3 immunoreactivity among AM subgroups:

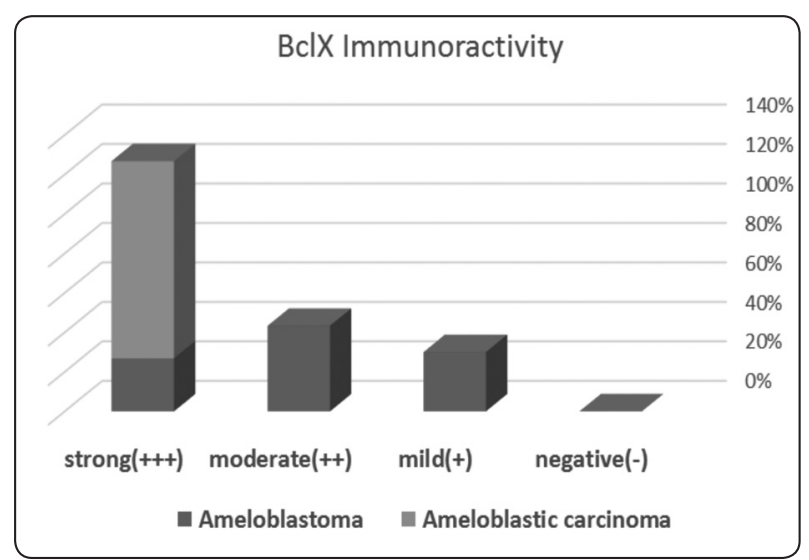

Chart (7): BcLX immunoreactivity among AC and AM:

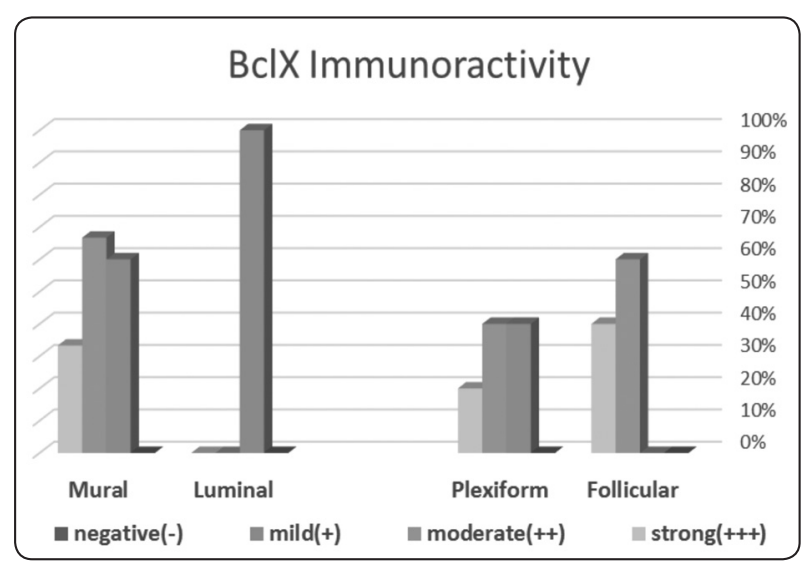

Chart (9): BcLX immunoreactivity among studied AM variants: 


\section{DISCUSSION}

Odontogenic tumors are a diverse group of osteo-destructive lesions with a wide range of clinical and biological characteristics. Diagnosis of odontogenic tumors can be challenging due to their rarity and diverse morphology ${ }^{[18-20]}$ In view of this fact, a growing number of studies have tried to identify epithelial and mesenchymal factors that participate in the regulation of their growth and determine the differences in behavior between these diseases. The rarity of malignant odontogenic tumors, variations in their pathogenesis and biological behavior all contribute to the difficulty in diagnosing them. Moreover, it may be difficult to distinguish some of these tumors from their benign counterparts and verifying their odontogenic origin can be challenging at times. The most obvious characteristics of malignant tumors are proliferation and migration ${ }^{[18-20]}$.

Epithelial proliferation and aggressiveness of cells determination help in investigating the differences between biological behaviors of various tumors ${ }^{[13]}$. As a result, immunohistochemical examination of cell proliferation activity has become a significant tool for providing useful information about behavioral biological differences of many cancers ${ }^{[11]}$.

MDM2, a $90-95 \mathrm{kDa}$ protein encoded by the $\mathrm{mdm} 2$ gene on chromosome $12 \mathrm{q} 13-14$, is one such marker for identifying proliferative activity and tumor aggressiveness. Because MDM2 is a negative regulator of p53 function, binding to the transcriptional activation region of p53 and causing proteasome-mediated degradation, overproduction of MDM2 protein increases the risk of cancer formation. Increased expression of MDM2 has been reported in several human cancers including breast carcinomas, malignant melanomas, esophageal carcinomas, and head and neck cancers, and associated with poor prognosis ${ }^{[21-23]}$.

The present work revealed that, MDM2 immunostaining was strong in AC than AM.
Meanwhile, between AM variants were expressed more in follicular conventional than plexiform and in mural unicystic than luminal type. These results agreed with Radi N.A.,2019 ${ }^{[19]}$ and Krishna A, et.al. $2012^{[21]}$ studies who reported that the positivity for MDM2 was observed in nucleus and cytoplasm of the peripheral and central stellate reticulum like cells, also statistically significant difference between $\mathrm{AM}$ and $\mathrm{AC}$ cases ${ }^{[19,21]}$.

Radi. N.A., 2019 ${ }^{[19]}$ concluded that MDM2 immunoreactivity was found predominantly in peripheral ameloblast like cells and it was also seen in central stellate reticulum like cells suggesting that peripheral cells essential and mean cell for evaluating the proliferative activity of AM. ${ }^{[18,19,21]}$

As well Kumamoto et al. (2004) ${ }^{[24]}$ found that elevated expression of MDM2-p53, p14 in benign and malignant AM suggested that alteration of MDM2-p53, p14 cascade leads to oncogenesis or malignant transformation of odontogenic epithelium and is associated also with tissue structuring and cytodifferentiation of $\mathrm{AM}^{[24]}$.

Radi N.A.,2019 ${ }^{[19]}$, Krishna A,et,al. 2012 $2^{[21]}$ and our results were in acceptance with a previous study that showed MDM2 positive expression in SCC was significantly higher than in normal oral mucosa and oral leukoplakia. Also, MDM2 expression in the lymph node metastasis was significantly higher than that without lymph node metastasis.

This interpreted by the fact that MDM2 mainly does its activity by downregulating the P53 tumor suppressor gene activity and its product. As, the two proteins form an autoregulatory loop in which p53 positively influences MDM2 production and MDM2 negatively controls p53 levels. Artificial disruption of this complex in cultured cells is enough to invoke p53-mediated gene expression and cell-cycle arrest MDM2 in response to DNA damage. So over expression levels of MDM2 decrease p53 protein levels and function, leading to gene amplification, accelerated tumor formation and progression ${ }^{[12,21-23,25,26]}$. 
Minichromosome Maintenance -3 proteins (MCM3) are proliferation proteins have gained special interest to predict the biological, clinical behaviors (prognosis) and diagnose of various pathologic lesions ${ }^{[13,14]}$.

In the current study, MCM3 immunoreactivity showed strong expression $\mathbf{5 0}>(100 \%)$ in all AC studied cases, meanwhile $43.3 \%$ of AM cases were moderately express the marker and $33.3 \%$ was mild expression. Conventional AM (follicular) was found MCM3 immunoreactivity than unicystic AM (mural).

These findings were consistent with JaafariAshkavandi Z.et.al.,2019 ${ }^{[27]}$ study who reported that MCM3 and Ki-67 was higher expression rate in OKC and ameloblastoma. MCM3 showed a higher expression rate than Ki-67 ${ }^{[27]}$. They concluded that, MCM3 might have a role in pathogenesis of odontogenic lesions and might be a reliable proliferation marker ${ }^{[14,27]}$.

In acceptance with prior results of papers in oral squamous cell carcinoma, papillary thyroid carcinoma, salivary gland tumors, and ameloblastic neoplasms ${ }^{[13,14,27,28]}$. MCM3 was found to be more abundant in tumor cells than $\mathrm{Ki}-67$ in all these studies. This result can be interpreted by differences in Ki-67 and MCM3 proteins expression during the cell cycle. However, Ki-67 expression is detected in the late G1 phase and may even be present in the $M$ phase and then disappears immediately, whereas MCM3 expression is seen in the early G1 phase, it's also possible that it's present in non-proliferating cells, prepared to enter the cell cycle, thus MCM3's prolonged-expression may make it easier to assess proliferation activity ${ }^{[13,27-29]}$.

Carreon- Barciage et al., 2015 [13] study demonstrated that MCM2 and MCM3 markers expression were shown to be more sensitive than Ki-67 markers in AM and AC, and as a result, they were better at predicting the biologic behavior of these tumors ${ }^{[13]}$.
In the current study, MDM2 and MCM3 proteins had exhibited higher expression in AC carcinoma than AM (follicular than plexiform in conventional variant and mural than luminal in unicystic variant) with a statistically significant difference between them. This indicates higher proliferation activity of these groups, which denotes cancer that is aggressive, invasive, and metastatic. Our results support the notion that MCM3 and MDM2 are more sensitive markers for detecting proliferating cells and better markers for evaluating tumor behavior. Although stromal component enzymatic activity is a cause of aggressiveness in $\mathrm{AM}$ and $\mathrm{AC}$, it has previously been suggested that these tumors' aggressive behavior is also related to epithelial features ${ }^{[29]}$. Both lesions show local aggressive behavior, and MCM3 might be considered a valid proliferation marker based on our findings and earlier research for these lesions $[13,14,29,30]$.

Other studies support our work as, Yoon et al. $2011^{[31]}$ and Bologna-Molina et al. $2009{ }^{[32]}$ demonstrated that $\mathrm{Ki}-67$ expression is higher in $\mathrm{AC}$ than in AM. This high level of expression was linked to the aggressiveness of AC. Low MCM2, MCM3, and MCM7 expression levels in medulloblastoma modified cells were linked to decreased invasion and migration, according to Lau et. al. $2010^{[33]}$.

The pathogenetic progression, molecular aberrations, and patient findings of ameloblastoma are all heterogeneous. Determining the molecular basis for these significant disparities is still a challenge. Discovering proteins that regulate tumor behavior, would be the first step toward understanding its pathobiology ${ }^{[18]}$. Ameloblastic carcinoma (AC), the malignant counterpart of ameloblastoma, is a development of a previously benign AM. ${ }^{[1,34]}$. The growth rate of tissues is determined by the balance between proliferative activity growth-promoting proto-oncogene and its growth-promoting cell death gene ${ }^{[16]}$. Neoplastic cells may have a higher rate of cell division and/or a lower rate of programmed cell death than normal cells ${ }^{[17]}$. 
Bcl-X, a newly discovered member of the Bcl2 antiapoptotic protein family ${ }^{[16]}$. Regarding Bcl-X immunoreactivity in the present work, there was a strong expression in all studied AC than AM. While in other groups follicular conventional ameloblastoma cases express more than plexiform, while mural unicystic ameloblastoma was noticed more than luminal type. These findings agreed with other reports as Shukla et.al. $2017^{[16]}$ who reported that $\mathrm{Bcl}-\mathrm{X}$ expression was seen increased in AM compared to the keratocystic odontogenic tumor and least expression in case of adenomatoid odontogenic tumor, this could indicate that ameloblastoma has a more aggressive biological behavior and higher cell survival activity ${ }^{[16]}$.

Kumamoto et al. 2004 ${ }^{[24]}$ found that expression of $\mathrm{Bcl} 2$ and $\mathrm{Bcl}-\mathrm{X}$ and inhibitors of apoptotic protein (IAP), survivin and XIAP in basal cells of ameloblastoma suggesting their role in suppression of apoptosis. And, they concluded that expression of apoptotic protease activating factor-1, cytochrome C, apoptosis inducing factor and caspase 9 in tooth germ and ameloblastoma suggested that apoptotic death of normal and neoplastic odontogenic epithelium is by mitochondria mediated apoptotic pathway. Increased apoptotic cell death in keratinizing cells in acanthomatous ameloblastoma, granular cells in granular cell ameloblastoma and malignant cells in Ameloblastic carcinoma. This interprets a role of apoptosis in cytodifferentiation, malignant transformation of odontogenic epithelium and treatment of various tumors ${ }^{[35]}$. Genes Mutations of any of the antiapoptotic proteins or any changes in the levels of their expression can lead to increased cell survival and contribute to the growth advantage of the affected tissues compared to the non-affected ones ${ }^{[36]}$.

The Bcl-X expression that is dysregulated causes DNA damage, which affects cellular function and permits the cell to remain in an antiapoptotic state, allowing it to continue growing. Owing to that, Bcl-X dysregulation can be a critical early event in the evolution of odontogenic tumors, and the degree of expression is linked to tumor aggressiveness $^{[17]}$. Moreover, Bcl-X governs programmed cell death by allowing tumor cells to avoid apoptosis, allowing them to survive and facilitate growth over the surrounding tissues and consequently resisting the therapeutic approach to radiation or chemotherapy, so we suggest a definite role of Bcl-X in the progression of these tumors ${ }^{[37]}$. This work was consistent with Mashhadiabbas et al. 2020 [38] study, which reported that the process of apoptosis in ameloblastoma is a sign of behavioral change in odontogenic epithelial cells especially in conventional ameloblastoma and that the apoptotic factors may not play an effective role in the malignancy of ameloblastoma ${ }^{[39]}$.

The results of the current research regarding the immunohistochemical expression of MDM-2, MCM-3 and Bcl-X proteins, revealed no statistically significant difference between immuno-expression and clinical data. This was consistent with other studies ${ }^{[14,31]}$ who proposed that proliferative capacity and clinical parameters have no apparent link. There was moderate positive correlation between studied immunohistochemical markers noted, but without statistically significant difference, this may be interpreted by small sample size of the studied groups. This work was in the same point of view with many authors who concluded that unicystic variant of AM is generally less aggressive than other ameloblastoma variants ${ }^{[1,34]}$. Also, this work agreed with WHO 2017 classification, which recognized that mural unicystic AM having the same biological aggressiveness, high recurrence rate and need same treatment as conventional ameloblastoma ${ }^{[1]}$.

\section{CONCLUSION}

High levels of MCM-3 and MDM-2 proteins expression could have a role in the pathogenesis of these tumors, serve as a reliable indicator of proliferative activity and a key indicator of the malignant transformation potential. 


\section{RECOMMENDATIONS}

Regarding AC, due to the rarity of this tumor, this study included only ten cases, thus our suggestions and hypotheses will need to be tested on a larger sample size. Mural unicystic ameloblastoma need further documentations.

\section{REFERENCES}

1. El-Naggar AK, Chan JKC, Grandis JR, Takata T, Slootweg PJ. WHO classification of head and neck tumours. WHO/ IARC classification of tumours. World Heal Organ. (2017)

2. Brown NA, Betz BL. Ameloblastoma: A Review of Recent Molecular Pathogenetic Discoveries. Biomark Cancer. Oct 4;7(Suppl 2):19-24. (2015)

3. Costa S, Pereira NB, Pereira K, Campos K, de Castro WH, Diniz MG1, Gomes CC3, Gomez RS. DNA methylation pattern of apoptosis-related genes in ameloblastoma. Oral Dis. Sep;23(6):779-783. (2017)

4. Khalele BA, Al-Shiaty RA. A novel marker of ameloblastoma and systematic review of immunohistochemical findings. Ann Diagn Pathol. Jun;22:18-24. (2016)

5. Brown NA, Rolland D, McHugh JB, Weigelin HC, Zhao L, Lim MS, Elenitoba-Johnson KS, Betz BL. Activating FGFR2-RAS-BRAF mutations in ameloblastoma. Clin Cancer Res. Nov 1;20(21):5517-26. (2014)

6. Kurppa KJ, Catón J, Morgan PR, Ristimäki A, Ruhin B, Kellokoski J, Elenius K, Heikinheimo K. High frequency of BRAF V600E mutations in ameloblastoma. J Pathol. Apr;232(5):492-8. (2014)

7. Kondo S, Ota A, Ono T, Karnan S, Wahiduzzaman M, Hyodo T, Lutfur Rahman M, Ito K, Furuhashi A, Hayashi T, Konishi H, Tsuzuki S, Hosokawa Y, Kazaoka Y. Discovery of novel molecular characteristics and cellular biological properties in ameloblastoma. Cancer MedApr;9(8):2904-2917. (2020)

8. Yoon HJ, Hong SP, Lee JI, Lee SS, Hong SD. Ameloblastic carcinoma: an analysis of 6 cases with review of the literature. Oral Surgery, Oral Medicine, Oral Pathology, Oral Radiology, and Endodontology. Dec 1;108(6):90413. (2009)

9. Saucedo LJ, Myers CD, Perry ME. Multiple murine double minute gene 2 (MDM2) proteins are induced by ultraviolet light. J Biol Chem; 274:8161-8. (1999)
10. Cahilly-Snyder L, Yang-Feng T, Francke U, George DL. Molecular analysis and chromosomal mapping of amplified genes isolated from a transformed mouse 3T3 cell line. Somat Cell Mol Genet.;13(3):235-244. (1987)

11. Onel K, Cordon-Cardo C. MDM2 and prognosis. Mol Cancer Res. Jan;2(1):1-8. PMID: 14757840. (2004).

12. Rayburn E, Zhang R, He J, Wang H. MDM2 and human malignancies: Expression, clinical pathology, prognostic markers and implications for chemotherapy. Curr Cancer Drug Targets; 5:27-41. (2005)

13. Carreon-Burciaga RG, Gonzalez-Gonzalez R, MolinaFrechero N, Bologna-Molina R. Immunoexpression of Ki-67, MCM2, and MCM3 in ameloblastoma and ameloblastic carcinoma and their correlations with clinical and histopathological patterns. Dis Markers.;683087. (2015)

14. Jaafari-Ashkavandi Z., Mehranmehr F., Roosta E. MCM3 and Ki67 proliferation markers in odontogenic cysts and ameloblastoma. Journal of Oral Biology and Craniofacial Research $9: 47-50$. (2019)

15. Blow JJ, Dutta A. Preventing re-replication of chromosomal DNA. Nat Rev Mol Cell Biol.6:476-486; (2005).

16. Shukla, Payal et al. "Comparative immunohistochemical study of Bcl-X in ameloblastoma, keratocystic odontogenic tumor and adenomatoid odontogenic tumor." Journal of oral and maxillofacial pathology: JOMFP vol. 21,1: 51-57. (2017)

17. Kumamoto $\mathrm{H}$ and Ooya K. Immunohistochemical Analysis of Bcl-2 family proteins in benign and malignant ameloblastomas. J Oral Pathol Med.; 28:343-9. (1999)

18. Radi N. A. Association of cortactin and mdm2 in solid Ameloblastoma and its malignant counterpart. EDJ. Vol. 65, 309:318, January, (2019)

19. Avelar RL, Antunes AA, Carvalho RW, Bezerra PG, Oliveira Neto PJ, Andrade ES. Odontogenic cysts: a clinicopathological study of 507 cases. J Oral Sci. 51:581-586. (2009)

20. Evangelou Z, Zarachi A, Dumollard JM, et al. Maxillary Ameloblastoma: A Review With Clinical, Histological and Prognostic Data of a Rare Tumor. In Vivo.34(5):2249$2258,(2020)$.

21. Krishna A, Kaveri H, Naveen Kumar RK, Kumaraswamy, KL, Shylaja S, Murthy S. Overexpression of MDM2 protein in ameloblastomas as compared to the adenomatoid odontogenic tumor. J Cancer Res Ther.; 2: 232-7. (2012) 
22. Bose I, Ghosh B. The p53-MDM2 network: From oscillations to apoptosis. J Biosci.; 32: 991-7. (2007)

23. Udeabor S. E., Adisa A. O., Lawal A. O., Barbeck M., Booms P., Sader R. A., Ghanaati S. PTCH-1 and MDM2 expression in ameloblastoma from a West African subpopulation: implication for chemotherapeutics. Pan African Medical Journal.; 20:140, (2015)

24. Kumamoto H, Ohki K, Ooya K. Expression of Sonic hedgehog $(\mathrm{SHH})$ signaling molecules in ameloblastomas. J Oral Pathol Med, 33:185-90, (2004).

25. Freedman DA, Wu L, Levine AJ. Functions of the MDM2 oncoprotein.Cell Mol Life Sci;55:96-107, (1999).

26. Cui JJ, Han XL, Wang WM. Expression and significance of p53 and mdm2 in patients with leukoplakia cancer. Asian Pac J Trop Med. 6: 831-4; (2013).

27. Jaafari-Ashkavandi Z, Najvani AD, Tadbir AA, Pardis S, Ranjbar MA, Ashraf MJ. MCM3 as a novel diagnostic marker in benign and malignant salivary gland tumors. Asian Pac J Cancer Prev APJCP.;14:3479-3482. (2013)

28. Valverde LF, de Freitas RD, Pereira TA, et al. MCM3: a novel proliferation marker in oral squamous cell carcinoma. Appl Immunohistochem Mol Morphol.;26:120-125. (2016)

29. Tsuneki M, Cheng J, Maruyama S, Ida-Yonemochi H, Nakajima M, Saku T. Perlecan rich epithelial linings as a background of proliferative potentials of keratocystic odontogenic tumor. J Oral Pathol Med.; 37:287-293, (2008).

30. Chae M. P., Smoll N. R., Hunter-Smith D. J., Rozen W.M., and Elsalanty M., "Establishing the natural history and growth rate of ameloblastoma with implications for management: systematic review and meta-analysis," PLOS ONE, vol. 10, no. 2, Article. ID e0117241, (2015).

31. Yoon H.J., B.C. Jo, W.-J. Shin et al., "Comparative immunohistochemical study of ameloblastoma and ameloblastic carcinoma," Oral Surgery, Oral Medicine, Oral Pathology, Oral Radiology and Endodontology, vol. 112 , no. 6, pp. 767-776, (2011).

32. Bologna-Molina R., Mosqueda-Taylor A., Lopez-Corella E., et al., "Comparative expression of syndecan-1 and Ki67 in peripheral and desmoplastic ameloblastomas and ameloblastic carcinoma," Pathology International, vol. 59, no. 4, pp. 229-233, (2009).

33. Lau K.-M., Chan Q. K. Y., Pang J. C. S., et al., "Minichromosome maintenance proteins 2,3 and 7 in medulloblastoma: overexpression and involvement in regulation of cell migration and invasion," Oncogene, vol. 29, no. 40, pp. 5475-5489, (2010).

34. Speight, P.M., Takata, T. New tumour entities in the 4th edition of the World Health Organization Classification of Head and Neck tumours: odontogenic and maxillofacial bone tumours. Virchows Arch 472, 331-339 (2018).

35. Bast BT, Pogrel MA, Regezi JA. The expression of apoptotic proteins and matrix metalloproteinases in odontogenic myxomas. J Oral Maxillofac Surg.; 61:1463-6, (2003).

36. Johnstone RW, Ruefli AA, Lowe SW. Apoptosis: a link between cancer genetics and chemotherapy. Cell 108: 153-164, (2002).

37. Suri C. The Immunohistochemical evaluation of the expression of Bcl-2 in squamous cell carcinoma. J Clin Diagn Res.; 3: 1891-9, (2009).

38. Mashhadiabbas F., Safarpour R. and Ghorbani H. Role of Apoptotic Biomarkers in Ameloblastoma and Dental Follicle. Journal Dental School; Vol 38, No.2, Spring; 69-73. ISSN 2645-4351, (2020).

39. Lalmand M, Boutremans E, Loeb I, Horoi M, Dequanter D and Javadian R. Ameloblastoma: Demographic, Clinical, and Histopathological Data, and Outcomes of Recurrence. J Dent \& Oral Disord.5(1): 1109; (2019). 